\title{
ORÁN Y EL COMERCIO GENOVÉS EN LA TRANSICIÓN A LOS TIEMPOS MODERNOS ${ }^{1}$
}

\author{
José ENRIQUe López de Coca CAstañer \\ Universidad de Málaga
}

\begin{abstract}
SUMARIO
1. Orán y los genoveses en visperas de la conquista española (14901509).- 2. Presencia genovesa en el presidio (1509-1535).- 3. Consideraciones finales. -4 . Documento.
\end{abstract}

La conquista de Granada y la posterior intervención hispana en el norte de Africa provocaron grandes trastornos en el tráfico marítimo veneciano, según he puesto de relieve en otro lugar ${ }^{2}$. Ahora me propongo examinar las repercusiones que tales acontecimientos tuvieron en Génova, cuyos intereses económicos en la zona superaban con creces a los de la serenísima república. A tal efecto analizaré los cambios registrados en el comercio genovés con el reino de Tremecén, haciendo hicapié en lás rela-

\footnotetext{
'Este trabajo ha sido realizado con cargo a los fondos del Proyecto de Investigación PS9.0052 que patrocina el Ministerio de Educación y Ciencia.

2J.E. LOPEZ DE COCA, Granada, el Magreb y las galeras inercantiles de Venecia en tiempo de los Reyes Católicos y Carlos 1. "1490: en el umbral de la Modemidad. El Meditemáneo europeo y las ciudades en el tránsito de los siglos XV-XVI". Valencia, 1994, I, pp. 2355.
}

"Anunrio de Estudio Medievales". 24 (19624) 
ciones que éste mantenía con el puerto andaluz de Málaga, pieza clave, en su momento, para la penetración ligur en el Magreb central ${ }^{3}$.

La importancia comercial de la ciudad de Tremecén se debŕa a su situación privilegiada. Auténtica encrucijada de caminos y rutas caravaneras, la capital zayaní contaba con dos salidas al mar: una cercana, Honein, y otra más distante, la ciudad y puerto de Orán. Ch. E. Dufourcq ha llamado la atención sobre la posible alternancia en la supremacía de uno u otro puerto durante la Baja Edad Media ${ }^{4}$. A fines del Cuatrocientos, sin embargo, parece que la ciudad de Orán se impuso definitivamente a su rival ${ }^{5}$. Se descargaban en su puerto alumbre, goma, laca y otras drogas y especias orientales, los bordates y paños de Castilla, Valencia, Languedoc, Flandes e Inglaterra, aparte del latón, piedras de cornalita y otros abalorios que se reexpedían al sur del Sahara por la vía del oasis de Tuat. De aqui llegaban el oro, los dátiles y las plumas de avestruz, si bien es cierto que la mayoría de las exportaciones oraníes procedían del propio país de Tremecén: cera, cueros, albornoces y, por supuesto, los famosos "hambeles"6.

\section{ORÁN Y LOS GENOVESES EN VÍSPERAS DE LA CONQUISTA ESPAÑOLA (1490-1509)}

Orán importaba manufacturas 'atlánticas y bienes orientales por medio de los barcos genoveses que seguran la ruta comercial Cádiz-isla de

\footnotetext{
${ }^{3}$ En este sentido, remito a los siguicintcs trabajos del profesor Jacqucs HEERS, Le royaume de Grenade et la politique inarchande de Gênes en Occident XVè̀ne siecle), "Le Moyen Age" LXIII (1957), pp. 119 y 120; Gênes au XVè̀ne siècle. Activité economique et problèmes sociaux, Paris, 1961, pp. 477-479.

${ }^{4} \mathrm{Cf}$. Liaisons inaritimes et commerce catalans, majorquins et valenciens avec le Maghrib, du XIle au XVe siècles, "Cuademos de Historia Económica de Cataluña", XX (1979), pp. 113 y 116.

'Téngase en cuenta, además, que seis kilómetros al oeste de Oran se encontraba el fonc dero de Mazalquivir, el más seguro de toda la costa norteafricana. De él escribe Andru Bemáldez que "es el propio puerto de Oran". Cf. Meinorias del reinado de los Reyes Católicos. Ed. M. Gómez Moreno y J. de M. Carriazo. Madrid, 1962, p. 491. Sustenta un punto de vista contrario Mahmud-Agha BOUAYED, Le port de Hunayn, trait d'union entre le Maghreb et l'Espagne au Moyen Age, "Relaciones entre la Península Ibérica y el Magreb (siglos XIIIXVI)", Madrid, 1988, p. 345.

${ }^{6} \mathrm{R}$. RICARD, La factorerie portugaise d'Oran (1483-1487), "Etudes sur les portugais au Maroc", Coimbra, 1955, pp. 193-201. Los "hambelcs" eran una especie de tapices o coberturas de lana con rayas de colores, muy apreciadas en los mercados de la orilla septentrional del Mediterráneo.
} 
Quíos, haciendo escala en diferentes puertos norteafricanos. Este sistema de navegación, conocido como per costeriam, venía de antiguo y se utilizaba, asimismo, para transportar pasajeros musulmanes de un extremo al otro del Mediterráneo en viajes que duraban a menudo una estación ${ }^{7}$. A fines del siglo XV funcionaba a pleno rendimiento: gracias a la nave "Goana", que en 1495 cruzó el mar interior desde Cádiz a Constantinopla, Orán recibió una importante partida de paños ingleses; dos años más tarde, en su puerto se descargarían grandes cantidades de laca traídas por la nave "Camilla", procedente de Alejandría ${ }^{8}$.

Los mercaderes genoveses también aparecen bien situados en el tráfico que unía el puerto tremeceni con los de Valencia y Marse!la. En 1495 zarpaba del Grao una nao vizcaína por cuenta de un comerciante ligur: llevaba en sus bodegas paños de la tierra y volvió al poco tiempo con un cargamento de dátiles. No es un hecho excepcional pues durante las dos últimas décadas del siglo salieron de Valencia hasta once barcos diferentes, capitaneados por genoveses, los cuales arribaron a Orán después de haber hecho escala en Cartagena o Almeria9 ${ }^{9}$. De Marsella venían las telas denominadas bordates, que eran objeto de gran demanda en todo el reino de Tremecén. Este negocio estaba casi monopolizado por Francisco y Lorenzo Cataneo, que en 1495-1496 trajeron a Orán varios miles de piezas del citado tejido a bordo de navíos de la Superba o galeazas francesas, que emprendían el tornaviaje cargadas de cueros, cera y dátiles ${ }^{10}$.

En noviembre de 1490 los Reyes Católicos otorgaron a la ciudad de Málaga el permiso necesario para reanudar el comercio con Berbería. Poco después el concejo malagueño tomaba la iniciativa de definir cuáles eran las mercancías que podían exportarse al otro lado del mar, contando para ello

\footnotetext{
'J. Heless, Gênes et l'Afrique du Nord vers 1450, "Anuario de Estudios Medicvales", 21 (1991), pp. 233-246.

${ }^{8} \mathrm{D}$. GlOFFrts, Il commercio d'importazione genovese alla luce dei registri del Dazio (14951537), "Studi in onore di Amintore Fanfani", V (Milano, 1962), pp. 123, 141-142 y 213.

${ }^{9}$ D. GIOFFRE, op. cit., p. 140; D. IGUAL LUIS, Italianos en la frontera mairitinks nazari: la ruta de Valencia a Granada en el siglo XV, "La frontera oriental nazari como sujutu histórico (s. XIII-XVI)", Lorca-Vera, 22-24/noviembre/1994. En imprenta.

${ }^{10}$ D. GIOFFRE, op. cit., pp. 168 y 169. Se trata de telas francesas que, en apariencia, nada tienen que ver con los bordates tradicionales (tcjidos de algodón fabrichdos en Egiplo).
} 
con la opinión de los comerciantes locales, genoveses inclurdos ${ }^{11}$. No obstante, las interdicciones reales del tráfico en los años siguientes harán que muchos intercambios se formalicen bajo la cobertura de la alfaquequería. En octubre de 1494, por ejemplo, los genoveses Bartolomé Barça, Martín - Centurion y Agustin Ytalian solicitaban licencia al concejo antes de sacar cierta mercadería para la redención de cautivos cristianos; tres años más tarde continuaban consagrados a esta actividad junto con su compatriota Marcos Scarçafigo, vecino de Granada ${ }^{12}$.

Esta especie de "comercio alternativo" se orientaba hacia los puertos de Tetuán, Vélez de la Gomera y Cazaza, de donde procedían los corsarios musulmanes que asaltaban por entonces las costas del reino de Granada. Las relaciones estrictamente mercantiles con el reino de Tremecén, empero, están documentadas desde fecha temprana ${ }^{13}$. Algunos contratos de fletamiento muestran a los comerciantes malagueños desplazándose hasta Orán a bordo de navfos que hacían escala en Almerfa. En el viaje de ida llevaban frutos secos, lino o seda morisca, volviendo con cera, grana y productos artesanales a cualquiera de los puertos comprendidos entre Alicante y Cádiz ${ }^{14}$. Por regla general, los genoveses residentes en Málaga participaban en este tráfico asociados con mercaderes locales. Caso, verbigracia, de Adan de Vivaldo y Francisco Muñoz, que el 24 de enero de 1504 tomaban a flete la nao vizcaina "Santa Marfa de Piedad", de 120 to-

\footnotetext{
"Una visión general en J. E. LOPEZ DE COCA, Relaciones mercantiles entre Granada y Berbería en la época de los Reyes Católicos, "Baetica", 1 (Málaga, 1978), pp. 299-311. En adelante citaré la segunda edición, inserta en J. E. LOPEZ DE COCA, El reino de Granada en la época de los Reyes Católicos. Repoblación, comercio y frontera, Granada, 1989, II, pp. 57. 88.

${ }^{12}$ (A)rchivo (M)unicipal (M)álaga, Actas Capitulares, libro $1^{\circ}$, fol. 302 y v.; (A)rchivo (H)istórico (P)rovincial (M)álaga, leg. 1 (1 de marzo y 28-29 de abril de 1497). En lo que concieme a estos protocolos notariales, citaré por la fecha del acta siempre que carezca de foliación o ésta no sea legible. Sobre la colonia genovesa establecida en Málaga después de la conquista, remito a rnis trabajos, Los genoveses en Málaga durante el reinado de los Reyes Católicos, "Anuario de Estudios Medievales", 10 (1980), pp. 619-650; y, en colaboración con $M$ - Teresa LOPEZ BELTRÁN, Mercaderes genoveses en Málaga (1487-1516). Los herinanos Centurion e Ytalian, "Historia. Instituciones. Documentos", 7 (1980), pp. 93-126.

${ }^{13}$ De aquí procede una partida de dátiles que Martin Centurion y Agustín Ytalian revenden al mercader malagueño Juan Diez. AHPM, leg. 1 (23/agosto/1497).

${ }^{14}$ Era en la misma Oran donde los comenciantes decidian a qué puerto deseaban volver. J. E. LOPEZ DE COCA, El reino de Granada, II, p. 68-70.
} 
neles, para efectuar un viaje de las características susodichas ${ }^{15}$. No hay que descartar, sin embargo, que prefirieran tratar directamente desde Almería por lo que da a entender Jerónimo Münzer a su paso por ésta en octubre de $1494^{16}$.

El convento mercedario de la Madre de Dios, instalado en Orán después de 1509, recibió la pequeña iglesia de San Martín "adonde antiguamente los xinobeses solfan dezir misa" ${ }^{17}$. He aquí un testimonio indirecto sobre la importancia que había alcanzado la colonia ligur en vísperas de la ocupación española. A ella pertenecían Francisco y Lorenzo Cataneo, a los que ya he mencionado en relación con el comercio de bordates. Consta que el primero exportaba grandes cantidades de "hambeles" a Castilla y Portugal al tiempo que negociaba con cera en el mercado gaditano. Un acta notarial genovesa revela, además, que tenía relaciones con la compañía de Agustin y Batista Spinola, con sede en Londres, a la que suministraba dátiles recibiendo paños ingleses en contrapartida ${ }^{18}$. Algunas de las actividades desarrolladas por Lorenzo Cataneo salen a relucir en las cartas despachadas por el rey Fernando en respuesta a las quejas presentadas por Felipe de Avenante, un mercader genovés que, tras una larga estancia en Valencia, se habra trasladado a Orán para dirigir la "casa de mercaduria" del citado Lorenzo. Al parecer, en enero de 1495 su hermano Batista habfa cargado aqui 46 fardos de cueros, ropa y piezas de oro en una nave bretona que después fue apresada por el corsario vizcaíno Juan Pérez de Carrión. En el mes de febrero siguiente, serf́a el propio Felipe de Avenante quien, yendo

\footnotetext{
${ }^{15}$ El trayecto previsto incluía una primera escula de 3 días "útiles" en Alhuñol para cargar fruta, y otra en Almeria, donde complctarian la carga y recibirian pasajeros. El contrato prohibe al macstre de la nao embarcar "ropa ninguna de increadería", cn cuanto a las quintaladas de la marinería, se admiten éstas siempre que no scan de fruta. AHPM, leg. 8, fol. 45 y 46.

${ }^{16} \mathrm{El}$ viajero alemán añade que de Alıncria a Oran se tardaba entre 12 y 20 horas según soplara el viento. Cf. Itinerarium Hispanicumn Hieronyıni Monelarii, Ed. L. Pfandl "Revuc Hispanique", XLVIII (1920), pp. 39 y 40.

${ }^{17}$ Así se lee en el pleito mantenido por los frailes con algunos vecinos de la ciudad sobre la posesión de ciertos bienes inınuchles. (A)rchivo) (G)eneral (S)imancas, Conscjo Real, leg. 7 , fol. 4 .

${ }^{18} \mathrm{D}$. GIOFFrê, op. cit., pp. 122 y 204. Sobre la relación de F. Catanco con Cádiz, véase J. M. BELLO LEÓN, Mercaderes extranjeros en Sevilla en tiernpo de los Reyes Católicos, "Historia. Instituciones. Documentos", 20 (1993), p. 61.
} 
de Génova a Orán con un cargamento valorado en 2.000 ducados, vió interrumpido su viaje a la altura de Cartagena por otro corsario vizcaíno ${ }^{19}$.

Un tercer miembro de este grupo familiar, Nicolás Cataneo, habra obtenido en 1490 una carta de seguro y salvoconducto para comerciar con los puertos del mediodía peninsular ${ }^{20}$. Doce años más tarde tendrá que comparecer ante el Consejo Real de Castilla para defenderse de las acusaciones contra él formuladas a raíz del registro de un navío suyo que, procedente de Gennova, habra sido detenido por una escuadra andaluza a la vista de Orán y conducido luego al puerto de Málaga. Según el procurador fiscal, el citado comerciante

\footnotetext{
llevaba en la dicha nao cosas vedadas, espeçialmente alunbre e azero, estando como está defendido por derecho divino e umano que las semejantes cosas no se puedan llevar a ticrra de moros, e que por lo aver llevado no solamente perdió la dicha nao con todas las mercaderias c aparcjos que en ella avía, mas que hera digno de muerte e de perdimiento de todos sus bienes e destar descomulgado 21 .
}

Pese a la retórica propia del caso, este incidente reúne todas las apariencias de un puro y simple acto de piraterfa: la escuadra en cuestión, que estaba integrada por navíos particulares y de la casa ducal de Medina Sidonia, habia sido movilizada exclusivamente para perseguir a los corsarios berberiscos 22 . Sea como fuere, Nicolás Cataneo debió salir absuelto del proceso pues lo volvemos a encontrar tres años después, como cónsul

\footnotetext{
${ }^{19}(R)$ egistro (G)eneral (S)ello. Simancas. Julio 1495, fol. 459 y 460; Documentos sobre las relaciones internacionales de los Reves Católicos, Ed. A. de la Torre, V (Bareclona, 1965), pp. 124 y 125.

${ }^{20}$ En la carta, firmada por don Femando en Sevilla a 18 de abril de 1490 , se alude a Nleolás Caltanco como un mercader que "sucle contratar en Oran". RGS, abril 1490, fol. 80.

${ }^{21}$ Se conoce este incidente gracias a la carta (Madrid, 12/diciembre/1502) que cl rey Católico envía al corregidor de Málaga ordenando que, a la espera de una sentencia definitiva, se devuelvan al genovés sus pertenencias por considerar que "la dicha nao resçibía perjuizio e estava a peligro en estar queda en el puerto de la dicha çibdad, c asy mesmo las mercaderías en no venderse". (A)rchivo (C)atedral (M)álaga, leg. 63, cuad. 86.

${ }^{22}$ Noticias sobre el annamento y objetivos de esta flota, en AGS, Contaduría Mayor de Cuentas, leg. 168. Si observamos que el genovés valoraba los daños sufridos en inás de 10.000 ducados, se entenderá el interés con que el duque de Medina Sidonia reclama su parte del botín. Véasc, en este sentido, la carta de poder que otorga (Sevilla, 4/novicmhre/1502) a su criado Antón Rodríguez. Lucero. ACM, leg. 63, cuad. 90.
} 
del rey Católico en Orán, prestando dinero a unos alfaqueques castella$\operatorname{nos}^{23}$.

***

A mediados del mes de septiembre de 1505 una fuerza expedicionaria al mando de don Diego Fernández de Córdoba, Alcaide de los Donceles, se apoderaba de la villa y fortaleza de Mazalquivir. La relación de la campaña escrita por Gonzalo de Ayora concluye con una noticia sobre el impacto provocado por esta conquista en la cercana Orán. Dice así:

Las nuevas de allí son quel sábado pasado ficieron pedazos a todos los judios y mercaderes de Orán, salvo a Franco Catanio quel Mezuar le salvó la vida; pero los biencs de todos fucron a sacomano ${ }^{24}$.

Este estallido de ira popular está sin duda relacionado con la creciente hostilidad que despertaba la comunidad hebrea residente en el reino de Tremecén, cuya vida se había desenvuelto hasta entonces dentro de los límites trazados por la ley canónica del islam. La llegada de refugiados sefardíes y la tensión provocada por la amenaza de una intervención cristiana contribuyeron a generar un clima de desconfianza hacia estos judíos que, como es sabido, servian de intermediarios a los comerciantes europeos en sus tratos con la población musulmana ${ }^{25}$. En cuanto a los genoveses, no parece que el episodio diera al traste con sus negocios en Orán ${ }^{26}$.

La carda de Mazalquivir, sin embargo, fue un toque de atención para todos los mercaderes que operaban en la zona; máxime si a partir de ese momento sus actividades van a verse estorbadas por las prohibiciones sucesivas del comercio que dicta la monarquía católica $a^{27}$. Burlarlas supo-

\footnotetext{
${ }^{23} \mathrm{Cf}$. apéndice documental.

${ }^{24} \mathrm{El}$ "mezuar" era una especic de lugarteniente o virrcy del sultán. Cf. (C)olección (D)ocumentos (I)néditos, XLVII (Madrid, 1865), p. 554 en particular.

${ }^{25}$ Merece la pena lecr cl excelente trahajo de John O. HuNWICK, The rights of "dhimmies" to maintain a place of worship: A 15th Century "fatwà" froin Tlemcen, "Al Qantara", XII (1991), pp. 133-155.

${ }^{26}$ En 1507, por ejemplo, una nave ligur llega al puerto de Génova, procedente de Oran, con un cargamento de cueros y plumas de avestru\%. D. GiolilkY:, op. cit., p. 204.

${ }^{27}$ AMM, Originales, I, fols. 233-234 y II, fol. 23; Provisiones, IV, fol. 213 y vo y V, fols. $32 v^{0}-35$.
} 
nía para los italianos arriesgarse a que las flotillas castellanas que patrullaban los accesos marítimos del reino de Tremecén registraran sus navíos buscando todo aquello que a los capitanes se les antojara declarar mercanć́as ilegales $^{28}$. Por este motivo, genoveses de Málaga como Bartolomé de Marin, Benito de Negron y su hermano Francisco, que solían tratar en Orán, trasladarán ahora sus intereses al puerto de Mazalquivir ${ }^{29}$.

La seguridad del comercio sólo estaba garantizada en aquellos casos donde mediara la oportuna licencia real; por ejemplo, la que don Fernando concedió en junio de 1507 a los hermanos Agustin y Pantaleón Ytalian para que enviasen un navío a Orán "por un viage solamente" ${ }^{30}$. Más que una concesión graciosa, se trataba de pagar los favores que dichos comerciantes y banqueros habían dispensado en los asuntos de Africa ${ }^{31}$. En este sentido, también hay que destacar la ayuda prestada al mantenimiento de Mazalquivir por Agustín de Vivaldo y Agustín de Grimaldo, genovés de Sevilla el primero y residente en Valencia el segundo, que por estas fechas ejercían como banqueros de la monarquía ${ }^{32}$. Durante el bienio 1507-1508 ambos genoveses adelantaron parte del dinero que necesitaba el Alcaide de los

\footnotetext{
${ }^{28}$ Caso de la nave de Lorcizzo de Franquis que, al decir de sus captores, llevaba artilleria, annas, hilo de cuerda para ballestas, velas y aparejos. Así consta en la respuesta que don Fermando dió a unos emisarios de Génova estando el monarca en La Spczia, en junio de 1507. A. RODRIGUEz VILLA, Un cedulario del rey Católico (1508-1509), "Boletín de la Real Academia de la Historia", LV (1909), doc. 471.

${ }^{29}$ Se deduce de la lectura de una carta de finiquito otorgada en Málaga (15/julio/1511) por Benito de Negron y Bartolomé de Marin sobre asuntos pendientes entre ellos. AHPM, leg. 4, fols. 127 y 128.

${ }^{30}$ Los citados genoveses no hicieron uso de la licencia hasta el año siguiente, scgún consta en la confimación de la misma expedida el 25 de mayo de 1508. A. RODRlGULz VilíA, op. cit., doc. 142. Vuelto a editar en E. IBARRA RODRIGUEZ, Documentos de asuntos económicos correspondientes al reinado de los Reyes Católicos, Madrid, 1917, doc. XLI, p. 92.

${ }^{31}$ Agustín Ytalian, concretamente, que adelantó 1.560 .000 maravedies para la campaña militar de Mazalquivir. AGS, Contaduria Mayor de Cuentas, leg. 195.

${ }^{32}$ Sobre Agustín de Vivaldo véase R. PIKE, Enterprise and Adventure. The Genoese in Seville and the Opening of the New World, Ithaca, 1966, pp. 170, 180 y 194. Agust in de Grimaldo vivió en Valencia hasta su muerte, en 1520, según los registros notariales del escribano Jaume Salvador (debo este dato a la amabilidad de David Luís Igual). Entre agosto de 1508 y mayo de 1509 el tesorero real Francisco de Vargas recibió siete órdenes diferentes para reembolsar a estos genoveses, en ducados de Castilla y florines de Aragón, otras tantas sumas que habian adelantado a los embajadores residentes en las cortes pontificia y francesa. A. RODRIGUEZ VILIA, op. cit., docs. 219, 445, 568, 570, 613, 614 y 634.
} 
Donceles, capitán general de Mazalquivir, a cuenta de las libranzas que éste tenía asignadas en varios partidos fiscales del reino de Castilla ${ }^{33}$.

Es evidente que los genoveses afincados en la Península habían decidido apoyar a la Corona en sus empresas africanas. Ahora bien, ¿que sucedió con aquellos otros comerciantes ligures que frecuentaban Orán, en especial los Cataneo? En el caso de Nicolás, cónsul del rey Católico, las fuentes no dejan lugar a dudas. Ausente de Orán cuando la población local persiguió a los comerciantes judíos y extranjeros -había venido a la Corte para cobrar las sumas prestadas a los alfaqueques reales ${ }^{34}-$, se apresu:ará a ofrecer sus servicios a don Fernando: en enero de 1506 partía de Málaga hacia Tremecén como portavoz de una misión diplomática cuya naturaleza desconozcoss.

Muy diferente será la postura adoptada por Lorenzo Cataneo, que residra ahora en Génova como cónsul de portugueses ${ }^{36}$. Bien porque no tenfa conciencia de los cambios que se estaban produciendo en el norte de Africa, o porque amaba el riesgo, lo cierto es que va a verse involucrado en uno de los incidentes navales más sonados de la épocá. En agosto de 1508 Marino Sanudo, siempre atento desde su atalaya veneciana a todo lo que ocurría en el Mediterráneo, anotaba en su diario la siguiente noticia recibida de Génova, por la vía de Milán,

\footnotetext{
${ }^{33}$ Por carta del 23/septiembre/1507 el rey asegura a Agustín de Vivaldo que las libranzas se harán efectivas llegado el momento. AGS, Cédulas de la Cámara, lihro 14, fol. 14 y vo. En diciembre de 1508 el tesorero Vargas recibia instrucciones para devolver a los inentados genoveses (en la feria de Medina del Campo del año siguiente) los 3 millones de maravedies que habian provisto para los gastos de Mazalquivir. AGS, Contaduria del Sucldo, leg. 70. Lo recoge Rafacl GUt7likrliz CRUZ en su tesis doctoral, pendiente de publicación, La presencia española en el norte de Afirca: el sisterna de presidios en la época de los Reyes Católicos (1497-1516), Málaga, 1994, II, fols. 458 y 459.

${ }^{4}$ Estando en Medina del Campo, en octubre de 1505, recihe del tesorero Ochoa de Landa 328.125 maravedíes en metálico y la promesa de que el resto, otro tanto, le será pagado con cargo a las rentas ordinarias de 1507. AGS, Casa y Sitios Reales, leg. 5, fol. 4.

${ }^{33}$ Llevaba consigo dos cartas credenciales finnadas por el secretario real Hemando de Zafra: una dirigida al "mezuar" de Tremecen, y la otra a nombre del jeque "Mohamed Abençalema Barcaçaba". AGS, Guerra Antigua, leg. 1314, fol. 76.

${ }^{36}$ Había ahandonado Oran antes de 1500, año en el que firma un contrato con el rey de Portugal para distrihuir 50.000 arrohas de azúcar de Madcira en los increados mediterráneos. D. GIOFFR' op. cit., pp. 132 y 170.
} 
che la nave Salvega, di botte 2.000, sora Armeria, da l'arma Yspana, capetanio Piero Navara, era stà presa et brusata; et questo, perche dicono portava arme in Barbaria ${ }^{37}$.

Génova se encontraba entonces bajo protectorado francés. De ahr que don Fernando se viera obligado a justificar el suceso en una serie de cartas remitidas a su embajador ante el Rey Cristianísimo. Al parecer, en noviembre de 1507 Lorenzo Cataneo había despachado una carraca con destino al pequeño puerto de Arceo, al este de Orán. Estando alli, su patrón fue avisado por el Alcaide de los Donceles, desde Mazalquivir, de la existencia de cartas patentes que prohibían el comercio con el reino de Tremecén, pero hizo caso omiso de la advertencia. Ahora, al comienzo del verano, Lorenzo Cataneo había enviado otra carraca, patroneada por Luca Salvago, al puerto de Honein. Su llegada a éste coincidió con la de un escuadrón al mando de Pedro Navarro, conde de Oliveto, "que iba a executar un ardid que llevaba contra los moros del dicho lugar". En la versión del citado almirante, los genoveses habían ayudado a los musulmanes en la escaramuza que se produjo seguidamente, razón que le llevo a tomar el navío por la fuerza y confiscar su carga ${ }^{38}$. Esta falta de neutralidad fue, desde luego, la circunstancia más grave a ojos del rey Fernando, quien, refiriéndose al robo de la carraca, señalaba en una de las cartas

que no solamente fue muy justa la toma della, mas aun el dicho Lorenzo Cataneo incurrió en pena de perder los bienes que en qualquier tienpo le pudiesen ser tomados y pudiesen ser habidos, y contra su persona se debe proçeder por todo rigor de justiçia ${ }^{39}$.

\footnotetext{
${ }^{37}$ I Diarii di Marino Sanudo, VII (Venczia, 1882), col. 615.

${ }^{38}$ Las cartas están fechadas a 9 y 30 de octubre de 1508, 3 y 9 de marzo del año siguiente. A. RODRJGUEZ VILLA, op. cit., docs. 301, 326, 452 y 471. Esta última apareció anterionmente en Martín de los HEROS, Hisloria del conde Pedro Navarro, "CODOIN", XXV (Madrid, 1854), doc. 9. El cronista Lorenzo de Padilla, que silencia la participación genovesa en la defensa de Honein, completa la versión anterior en unos ténninos que encajan con la noticia recogida por $M$. Sanudo. Dice así: "volviéndose con esta carraca a Málaga, en el camino se quemó por cicro desastre, de manera que sc perdió la mayor parte de la mercadería que en ella venía". Cit. Crónica de Felipe I llainado el Hermoso, "CODOIN", VIII (Madrid, 1846), pp. 164 y 165.

${ }^{39}$ Doc. 326, p. 199 en particular.
} 
Ignoro si estas amenazas llegaron a cumplirse o no. Pero resulta significativa la carencia de noticias sobre estos Cataneo tras la toma de Orán por los españoles.

\section{Presencia genovesa en el pResidio (1509-1535)}

Si analizamos el reparto del botín obtenido en la conquista de Orán, el 17 de mayo de 1509, comprobaremos que hubo participación genovesa en la misma, si bien a título particular. Ambrosio Grifo, por ejemplo, que pago 11.425 maravedres a los receptores del quinto real por cinco esclavas con sus hijos; o el marino Anton Corço, vecino de Málaga y dueño de una nao que puso al servicio del Alcaide de los Donceles después que éste asumiera el gobierno del nuevo presidio ${ }^{40}$. En lo que toca a la ayuda financiera, Agustín de Grimaldo adelantaba ese mismo año 2.000 ducados para sufragar los primeros gastos de la defensa de Orán. En 1510, serían los hermanos Ytalian quienes anticiparon otras cantidades a don Diego Fernández de Córdoba, aunque en circunstancias algo confusas pues consta que el noble andaluz los llevó a los tribunales a causa de una disputa "sobre çiertos canbios e yntereses" 41 .

Es probable que los genoveses pretendieran de este modo asegurarse una posición ventajosa en el comercio orani, que no tardaría en reanudars $\mathrm{e}^{42}$. Pero, de ser así, sus esperanzas se vieron defraudadas muy pronto. El 15 de enero de 1510 firmaba el rey Fernando un "asiento" con su tesorero de Valencia, Alonso Sánchez, concediéndole el monopolio de la contratación con los reinos de Tremecén y Tenez durante cuatro años a

\footnotetext{
${ }^{40}$ El pago lo haría efectivo Polo Batista de Franquis, mercader genovés de Málaga, quicn se encargó, asimismo, de negociar con los esclavos traídos por otros combatientes. AGS, Contaduría Mayor de Cuentas, leg. 223, según R. GUTIÉRREZ CRUZ, op. cit., II, fol. 468. $A H P M$, leg. 75 (4/agosto/1514). En cuanto a Anton Corço, un escrito de pedimiento, con testigos, muestra que en 1515 se había visto forzado a pagar de su bolsillo el sueldo de la tripulación. AHPM, leg. 28 (19/febrero/1516).

"AGS, Contaduría Mayor de Cuentas, leg. 200, según R. GUTtERrez CRUZ, op. cil., II, fol. 364. Agustín y Pantaleon Ytalian cobraron ese año una libranża de 660.000 maravedies que don Diego tenía asignada en el "servicio" de la provincia de Jaén. AHPM, leg. 3, fol. 336 y vo; 348 y $v^{0}$. Las noticias sobre el pleito con los genoveses figuran en AGS, Cédulas de la Cámara, libro 25, fol. 355.

${ }^{42}$ Sobre la recuperación de los intercambios véase Ch. de la VERONNE, Oran et Tleinsen dans la première inoitié du XVle siècle, Paris, 1983, pp. 16 y 17.
} 
cambio del $50 \%$ de los beneficios ${ }^{43}$. Semejante concierto dur6 poco debido a la fuerte oposición que generó en Cataluña, Mallorca y, finalmente, el reino de Granada después que el monarca lo extendiera al comercio realizado con Vélez de la Gomera ${ }^{44}$. Mientras estuvo en vigor, empero, dí pié a que se multiplicaran los conflictos. Gracias a los buenos oficios de Agustín Ytalian, regidor de Málaga desde 1508, una provisión real expedida el 14 de junio de 1511 confirmaba el derecho de la ciudad a traficar libremente con el norte de Africa. Al amparo de la misma, este genovés y su hermano Pantaleon aparejaron una nave con mercaderías para Orán, la cual fue embargada por el Alcaide de los Donceles siguiendo instrucciones del mentado tesorero ${ }^{45}$.

La libertad de comercio llegaría al normalizarse las relaciones con Tremecén mediante la firma de una tregua por cinco años, la cual inclufa el pago de un elevado tributo de parte musulmana. Estando el rey Catolico en la ciudad de Burgos, en diciembre de 1511, recibio a una embajada zayaní que trafa el encargo de "redactar los convenios y tratados de comercio con la ciudad de Orán"46. Tres meses más tarde, la Corona aceptaba los 4.687.000 maravedíes anuales que ofrecían Alonso de Sevilla y Gilberto de Santa Fe por el arrendamiento, hasta 1516, de los derechos de almojarifazgo y otras rentas de Orán y Mazalquivir, las cuales habrían de ser recaudadas como "se acostunbró pagar e cobrar e levar en la dicha çibdad de Orán

\footnotetext{
${ }^{43}$ A. DIAZ BORRÁs, La casa de contratación de Oran y el cainbio de filosofía de las transacciones entre Berberia y Valencia, 1510-1514, "Sharq al-Andulus", 9 (1993), pp. 19-27.

4J. E. LOPF:Z DE COCA, El reino de Granada, 11, pp. 76-78.

${ }^{45}$ En aquella nave "yva por nuestro fator Antonio Riçio" declara Agustín Ytalian ante notario el 25 de agosto de 1511 . Temiendo que se pierda el cargamento al no poder venderse, el genovés se compromele a "que dando e entregando el dicho Antonio Riçio, nuestro fator, las dichas mercaderias que asy nos fueron enbaraçadas, libre e descnbargadamente por ante escrivano público, que de agora yo el dicho Agustín Ytalian... me constituyo por depositario de todas las dichas mercaderías e prometo e me obligo de acudir con las dichas mercaderías o con los dineros que dellas se ovieren fecho e fuese vendidas..." cada ve\% que se lo pidan. $A H P M$, leg. 4, fol. $337 v^{0}$ y $338 ; R G S$, abril 1512 , sin foliar.

${ }^{46}$ Esta tregua, valedera a partir de junio de 1511 , había sido negociada en Oran y confirmada por el sultán en el mes de octubre. Ch. de la VERONNE, op. cir., p. 20. Pedro Mártir de Anglería señala en una carta del 4 de julio que los moros se habían comprometido a pagar 13.000 doblas al año en concepto de "parias" y a no contratar con los cristianos fuera de Oran; en cartas posteriores da cuenta de la estancia de los embajadores tremecenies en Burgos. Cf. Epistolario de Pedro Mártir de Anglería. Ed. y trad. José López. de Toro "Documentos Inéditos para la Historia de España", t. X (Madrid, 1955), docs. 456 y 471; 1. XI (Madrid, 1956), doc. 482. Lorenzo de Padilla rebaja el monto del tributo a 11.000 doblas anuales. Cf. Crónica de Felipe I, pp. 192 y 193.
} 
en tienpo que era de moros" ${ }^{47}$. Ambos arrendadores, uno granadino y judeoconverso valenciano el otro, representaban a los dos grupos de mercaderes que habían acudido al presidio norteafricano para sacar provecho de un comercio cuya rentabilidad parecía segura ${ }^{48}$. En este sentido, llama la atención que del capítulo de los metales, tradicionalmente considerados como mercancías vedadas, quedasen excluídas

las vergas de laton con mezcla de cobre, de gordeza de un dedo pulgar de la mano y de largo de quatro palmos poco mas o menos, que son para hazer manillas para las negras, para los hraços e para los pies, que sirven para llevar a la Zahara, e no se gastan ni han de gastar en otra manera ${ }^{49}$.

Debo advertir, sin embargo, que a la sombra de estos arrendadores se movían otros intereses, concretamente genoveses, como lo prueba el hecho de que a la hora de pujar presentaran como fiadores a comerciantes ligures residentes en los reinos de Castilla y de Valencia. Más aún: el artículo $1^{\circ}$ de las condiciones del arrendamiento establecía que sólo los recaudadores podrían contratar "los bordates anchos e angostos e veinteneros... o quien su poder oviere, e no otra persona alguna, so pena de los aver perdido". Alonso de Sevilla y Gilberto de Santa Fe se apresuraron a traspasar la exclusiva de estas telas a la "conpañfa" de Agustín de Grimaldo y Juan Vázquez, regidor de Murcia, por un precio de 4.000 ducados anua-

\footnotetext{
${ }^{47}$ Quedaban exentos los bienes y mercancías que trajeran los vecinos de la ciudad por su cuenta, o para su provisión, salvo drogas y especias, a condición de que lo declarasen previamente en la aduana. AGS, Escribanía Mayor de Rentas, legs. 132 y 133. Una copia de las condiciones del arrendamiento hecha por la Contaduría Mayor de Cuentas en septiembre de 1514, es la que glosa $M^{*}$ T. LOPLZ BELTRÁN, Fiscalidad regia en los puertos del reino de Tremecen: datos para su estudio, "Baetica", 8 (1986), pp. 314-316. Quc se mantuvieran los mismos impucstos de época islámica es un requisito que ya figuraba en el contrato de Alonso Sánchez. Un documento de fecha posterior menciona los siguientes: el diezmo de entrada de las mercancias y, una vez puestas a la venta, el derecho de "trujamanería", estimado en un $1 \%$ del valor de aquéllas, y otro de cuantía imprecisa, conocido como derecho de "caidia y puertas". RGS, marso 1517, sin foliar.

${ }^{48}$ El mercader Alonso de Sevilla hahia tratudo en Oran antes de la conquista como factor de Gonzalo Fernández. Elcano, también granadino. RGS, enero 1505, sin foliar. Gilbero de Santa Fe se hahía establecido en Granada huyendo, acaso, de la Inquisición valenciana. Un documento notarial de 1510 nos lo presenta adquiriendo ciertas balas de papel del genovés Agustín de Lomelin. J. de la OBzRA SII:RRA. Mercaderes iralianos en Granada (1508-1512), Granada, 1992, doc. 9. Para su relación con el Santo Ofício, véase R. GARCla CARCEL, Los origenes de la Inquisición española. El tribunal de Valencia (1478-1530), Barcelona, 1976, p. 294.
}

${ }^{49}$ Mercancía que solían transportar las galeras de Venccia, ausentes de Oran por esas fechas. J. E. LOPEZ DE COCA, Granada, el Magreb y las galeras mercantiles, p. 39. 
les. Expresado en otros términos, una parte sustancial del comercio de Orán, pues suponía casi un $20 \%$ de los ingresos globales previstos, pasaba a manos de un genovés que habra apoyado desde el principio la expansión española en el Magreb ${ }^{\text {so }}$.

Las perspectivas que ofrecía el comercio oranf se vieron truncadas a causa del deterioro de las retaciones con el sultán de Tremecén, que se mostraba incapaz de pagar con regularidad sus "parias". A comienzos de 1514 don Fernando tomó represalias sobre los mercaderes musulmanes y judíos que venfan a contratar en el presidio, los cuales fueron tomados como rehenes procediéndose a vender sus bienes para compensar el tributo no percibido ${ }^{51}$. De resultas de esto, la quiebra de los arrendadores fue casi inmediata. En el mes de septiembre la Corona nombraba receptor de las rentas de Orán al "veedor" Luis Mexía, quien apenas logró recaudar un millón de maravedíes aquel año. En enero de 1515 la gestión hacendística pasaba a depender de don Diego Fernández de Córdoba, marqués de Comares desde 1512, el cual arrendo en 9.000 ducados los derechos de la contratación según los tenían Alonso de Sevilla y Gilberto de Santa $\mathrm{Fe}^{\mathrm{s}^{2}}$.

A decir verdad, la carda del comercio fue más grave de lo que a simple vista parece. Coincidiendo con la toma de rehenes, y estando fuera de Orán don Diego, las autoridades locales cometieron diversas exacciones sobre la comunidad hebrea residente en la plaza, so pretexto de que cele-

\footnotetext{
${ }^{5}$ Se sabe muy poco de este Juan Vázquez. El 26 de mayo de 1509 el rey Femando escribía a la comunidad de Florencia intercediendo en favor del citado regidor murciano, a quicn debían 909 ducados de oro la compañía de Bardovilte y los herederos de Migucl de Calvia, mercaderes florentinos. A. RÓDRJGUEZ VILLA, op. cit., doc. 640. No he encontrado nada, sin embargo, en el importante trabajo de F. CHACÓN, Murcia en la centuria del Quinientos, Murcia, 1979.

31En las cuentas de Cristóbal Rejón, tesorero y pagador de Oran, uparecen una seric de gastos en relación a estos rehenes hechos entre los ineses de mayo y septicinhre de 1514. AGS, Contaduría Mayor de Cuentas, leg. 187, según R. Gu'TtÉRREZ CRUY, op. cit., I, fols. 77 y 78. Sobre las dificultades de Tremecen para satisfacer el tributo, véase Ch. de la VI:RONNI:, op. cit., pp. 20-22.

${ }^{52} L o ́ p e z$ Beltrán, que anota el nombramiento del citado receptor y no sabe explicarlo, añade gratuitamente que Mexía cobró también los 4.687 .500 maravedies estipulados en el arrendamiento. Me temo que desconoce los mecanisinos de funcionamiento de la Hacienda Real de Castilla. Cf. Fiscalidad regia, pp. 307 y 309. El acuerdo con el imarqués de Comarcs entraria en vigor a partir del incs de abril de 1515 según R. GUTTŔRRI:Z CRUZ, op. cit., I, fol. 121 .
} 
braba sus ritos religiosos subrepticiamente ${ }^{53}$. Una vez libres, estos judíos huyeron a Tremecén y se negaron a volver hasta que el pesquisidor Lope Hurtado de Mendoza, que vino a Orán en el verano de 1515, no les ofreció garantías de todo tipo. Según leemos en una carta del bachiller Castañeda, su secretario, la marcha de los hebreos "fue cabsa de deshazer del todo el trato desta çibdad"; y si ahora se les prohibe que observen el culto en la intimidad de sus domicilios,

estos judios no estarán aquí, y sin ellos no vale nada el trato desta çibdad porque moro ninguno conprará sino por mano de judio por cosa del mundo..."st.

Los genoveses de Málaga hacían grandes negocios en el presidio antes de que se produjera la quiebra fiscal. Caso de Agustín Ytalian, que reclamó una vivienda para su factor Antonio Riçio alegando que la presencia de éste en Orán beneficiaba a los vecinos y a las rentas reales ${ }^{55}$. $O$ de Flerigo Centurion, que introducía partidas de seda morisca y exportaba cueros vacunos para su reventa en Cádiz ${ }^{56}$. Un viejo conocido, Adan de Vivaldo, habra negociado en la plaza mientras la contratación estuvo monopolizada por Alonso Sánchez, asociándose luego con Agustín de Vivaldo y Agustín de Grimaldo ${ }^{57}$. Al parecer, tenían en Orán a un factor francés, Esteban Orran, que en 1512 importó por cuenta de estos genoveses 70 paños floretes de Córdoba, 2 quintales de seda de Granada, 25 docenas de

${ }^{33}$ CODOIN, XXXVI (Madrid, 1860), p. 508. El mercader Samucl Zatorra, rabino de esta comunidad, había recibido perniso del rcy (Valladolid, 30/septicmbre/1509) para dirigir el culto en su propio domicilio. AGS, Cámara-Pueblos, leg. 14.

${ }^{\text {s4 }}$ Y agrega que no existen inotivos para que dejen de celebrar su liturgia en privado; máxime si en la propia Roma, donde reside el papa, hay una sinagoga. AGS, Cámara-Personas, leg. 13, sin foliar.

${ }^{35}$ En septicinbre de 1514 la Corona ordena al repartidor Diego de Chinchilla que le entregue una casa, si la hubicre vacante. AGS, Cédulas de la Cámara, libro 33, fol. 88.

${ }^{56}$ Reclaına a Jacome Dimitrio, genovés de Cádiz, el precio de 1.300 cueros que le había vendido. AHPM, leg. 4 (26/junio/15/2). El 16 de agosto del año siguiente apodera a Adan de Vivaldo para que cobre, en su nombre, las ganancias habidas de 250 libras de seda que había enviado a Oran. AHPM, leg. 17, fol. 609 y vo.

${ }^{57}$ El 24 de encro de 1511 otorgaha poderes a Bartolomé de la Cruz, genovés morador en Orín, para cobrar cicrtas sumas que le debian en ésta. AHPM, leg. 13 , fols. $81 v^{\circ}-82 v^{\circ}$. Al año siguiente, vuclve a encomendarle que se encargue de sus intereses en la plaza. AHPM, leg. 20 (27/scptieinhre/1512). 
bonetes y 3.700 varas de frisa, aparte de otras mercancías, "lo cual podría valer a común estimaçión tres mill e trezientos ducados de oro"s8.

Es sabido que los comerciantes y marinos franceses frecuentaban el puerto de Orán en época musulmana, y que seguirán haciéndolo después de 1509 a pesar de que sus intereses se vean afectados por los contínuos en-

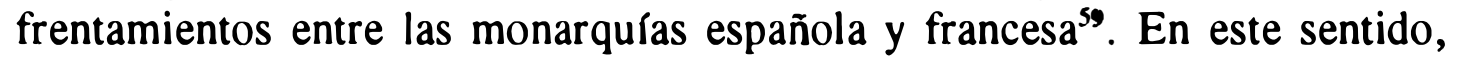
la guerra de la Liga Santa dejaría no pocas secuelas: el 19 de junio de 1513 la Corona despachaba una carta de salvoconducto en favor de Tristan Tepa, Pedro Arquier y Guillermo Tufano, mercaderes de Montpellier que habran abandonado Orán "a cabsa de las guerras pasadas" y no se atrevían a volver por temor a ser "maltratados e robados"60; un mes más tarde, el genovés Francisco de Negron reclamaba a un agente del Alcaide de los Donceles compensaciones por el daño causado a su hermano Benito al requisarle, en Orán, "çiertos fardos de grana e cueros" que había cargado en una nao francesa ${ }^{61}$. Con todo, lo que me interesa destacar aqui es que fueron estos mercaderes quienes arrebataron a los genoveses el comercio de los bordates. Sucedió, al parecer, durante la quiebra fiscal de 1514, cuando, en circunstancias que ignoro, Alonso Sánchez se hizo cargo de la contratación de las telas citadas por el mismo precio que la tenía arrendada Agustín de Grimaldo $^{62}$. A partir de entonces, el tesorero de Valencia figurará como "arrendador mayor" de los bordates, si bien el negocio va a estar realmente

\footnotetext{
${ }^{58}$ Esto sale a relucir en la carta ejecutoria (Madrid, 1/marıo/1517) de una sentencia dictada contra el citado factor, que había escamotcado cl pago de ciertos derechos fiscales. RGS, marzo 1517, sin foliar.

${ }^{59} \mathrm{~J}$. GUIRAL, Les relations commerciales du royaume de Valence avec la Berberie au XVe siècle, "Mélanges de la Casa de Vclázqucz" X (1974), p. 125. Algunos datos en R. Coluer y J. BILIJOUD, Histoire du cominerce de Marseille. III: 1480-1599, Paris, 1951. La embajada tremecení que pasó a Castilla en 1515, lo hizo a bordo de la nao francesa "San Vicencio". AGS, Contaduria Mayor de Cuentas, leg. 187.

${ }^{\infty}$ Esta carta de seguro fue concedida a instancias de los propios recaudadores de las rentas de Oran, lo que no deja de ser significativo. RGS, Contaduria Mayor de Cuentas, leg. 187.

${ }^{61}$ La reclanación, por valor de 60.250 maravedícs, scría presentada en Málaga ante Pedro Fermández de Bacna, factor y "haz.edor" del citado alcaide. AHPM, leg. 17, fol. 605 y vo . El embargo se produjo a pesar de una provisión real, del 27 de julio de 1512, que disponía que los genoveses no se vieran perturbados por la guerra en curso con el rey de Francia. AMM,

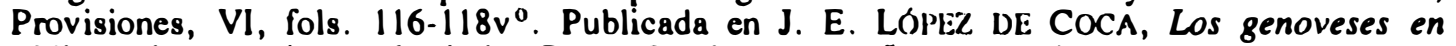
Málaga durante el reinado de los Reyes Católicus, doc. 5 del apéndice.

${ }^{62}$ Noticia inserta en las cuentas del "veedor" Luís Mexía. R. GUTTÉRREZ CRUZ, op. cit., I, fol. 415 y 416.
} 
en manos de Tristan Trepa como "arrendador menor" de la mentada contratación ${ }^{63}$.

No será éste el único retroceso que registre el comercio genovés en el presidio de Orán. Las fuentes que vengo manejando nada dicen de las escalas hechas en su puerto por los navíos ligures que iban y venían per costeriam. Cabe la posibilidad de que este sistema de navegación se viera trastornado por el incremento de la piratería en el Mediterráneo occidental a causa de los turcos ${ }^{64}$. Tambien, que hubiera perdido rentabilidad al ser abandonado por los musulmanes como medio de transporte porque ya no lo consideraban seguro ${ }^{65}$. Creo, no obstante, que los motivos de esta ausencia fueron otros: dada la naturaleza del tráfico realizado por los barcos que navegaban per costeriam, estos no podían correr el riesgo de fondear en lugares conflictivos como Orán y, consecuentemente, los evitaban ${ }^{66}$. Téngase en cuenta, a este respecto, el testimonio de León el Africano sobre la llegada de un navío genovés a Honein con el propósito de negociar directamente con los musulmanes ${ }^{67}$.

\footnotetext{
${ }^{63}$ En 1516 solicitan un descuento a los contadores mayores porque las ventas habían disminuído al faltar los mercaderes de Tremecén. RGS, mayo 1516, sin foliar. No obstante, los bordates seguían llegando al consumidor muslime por la vía de las "generosidades necesarias". En 1515 Cristóbal Rejón pagaba a Tristán Tipa 115.000 maravedíes po: 220 piezas que se habían entregado al régulo de Tenez. Ch. de la VERONNE, op. cit., p. 31 .

${ }^{6}$ En 1514 Génova envió una escuadra a las aguas de Trapani para esperar a los barcos que venían de Quíos e Inglaterra, los cuales corrían peligro a causa de los turcos que operaban desde Djerba. A. TENENT1, I corsari in Mediterraneo all'inizio del Cinquecento, "Rivista Storica Italiana" (1960), p. 281.

${ }^{65} \mathrm{~A}$ comienzos del siglo XVI corsarios portugueses secuestraron a 60 tunecinos que venían de Alejandría en una nave genovesa. El califa hafsi acusó a los italianos de no haberse molestado en defender a sus pasajeros y tomó represalias sobre los comerciantes que trataban en sus dominios, provocando así una nuptura de relaciones con Génova que se prolongó hasta 1507. D. GIOFFRE, op. cit., pp. 200 y 201. Sohre la pérdida de prestigio que esto supuso para la Superba hay una referencia indirecta en fuentes venccianas. J. E. LOOPEZ DE COCA, Granada, el Magreb y las galeras imercantiles, pp. 27 y 28.

${ }^{66}$ Los comerciantes y transportistas que seguian esta ruta buscaban, en cada escala, establecer contactos con el interior del ptís, abrir nuevos increados, etc. J. HEERS, Génes et l'Afiique du Nord, pp. 241-243.

${ }^{67}$ Sucedió hacia 1512-1513. Cf. Description de l'Afrique. Trad. A. Epaulard, Paris, 1956, II, pp. 329 y 330.
} 
Recién inaugụrada la regencia cisneriana el Consejo Real dictó una provisión en favor de los mercaderes extranjeros que trataban en Orán, garantizándoles que no sufrirían daño en caso de que se produjera una ruptura con sus países de origen ${ }^{68}$. Se pretendra, en definitiva, acabar con los desafueros anteriores en unos momentos en los que las relaciones con Tremecén pasaban por un trance delicado, que se agravará luego con la invasión turca y la ocupación temporal de la capital zayaní por Aruj Barbarro$\mathrm{ja}^{69}$. La estabilidad volvió a partir de octubre de 1521 , coincidiendo con la firma de un tratado por ocho años en el que se mantenfa la exigencia de un tributo anual, ahora sensiblemente rebajado ${ }^{70}$. Este acuerdo vino seguido de otro arrendamiento de los impuestos de Orán, una de cuyas cláusulas prescribía que todos los que desearan comerciar con cualquiera de los puertos comprendidos entre Argel y el estrecho de Gibraltar, debf́an acudir previamente al presidio para notificarlo a los recaudadores y pagar los derechos correspondientes. Requisito disparatado, que muchos ignoraron cada vez que pudieron, pone de manifiesto, sin embargo, el descenso del tráfico mercantil en Orán y, por tanto, de las rentas devengadas del mismo ${ }^{71}$.

Los genoveses han perdido definitivamente la partida ante sus rivales franceses en lo que toca al comercio de bordates, telas que seguran trayéndose de Marsella por cuenta, ahora, de los hermanos Juan y Perceval Reiner $^{72}$. De la generación de mercaderes instalados en Orán después de

\footnotetext{
${ }^{68}$ Expedida en Madrid el 30 de mayo de 1516, la carta promete que, llegado el caso, los mercaderes afectados dispondrán de tiempo suficiente "para que libre e seguramente se puedan yr a sus casas con todos sus bienes y haziendas que tovieren sin que les sea pucsto enbargo ni ynpedimento alguno...". RGS, mayo 1516, sin foliar.

${ }^{69} \mathrm{Ch}$. de la VeronNe, op: cil., pp. 24-26.

${ }^{70}$ Se fijan en 5.000 doblas porque, al decir del sultán, "su estado de rentas cs poco". En lo que concieme a la contratación de Orán, en el capítulo $4^{\circ}$ se confirma la exención del pago de impuestos para las provisiones que se lleven al presidio "eçebto de los dátiles que han de pagar los derechos, como de las mercaderías"; esto ilustra sobre una posible fuente de fraude. P. MARIÑo, Tralados intermacionales de España. Carlos V. II: España-Norle de Africa, Madrid, 1980, doc. 3 .

"Así reza en carta de Carlos I (Burgos, 14/abril/1524) amenazando a los posibles contraventores. $A M M$, Provisiones, $\mathrm{X}$, fol. 163-165. La ciudad de Málaga tuvo que esperar hasta 1528 para verse exenta de esta fornalidad, que, por otra parte, casi nunca cumplió. $A M M$, Provisiones, $\mathrm{XI}$, fol. $25 \mathrm{v}^{\circ}-30 \mathrm{v}^{\circ}$.

${ }^{72}$ En 1529, fecha en al que fucron arrestados a causa de la gucrra con Francia, anbos ejercían como arrendadores de la "provisyon del partido de los bordates". Ch. de la VERONNE, op. cit., pp. 36 y 37 . Los inercaderes francescs exportaban cera, dátiles y plumas de avestruz; parte de estos cargamentos llegaban a Génova a través de Marsclla. D. GiOlikrt, op. cit., p. 173.
} 
la conquista sobresale Antonio Riçio, quien, por la época de la intervención turca, tenía tratos directos con las caravanas que atravesaban el desierto. En la carta que mandó a Lope Hurtado el 27 de febrero de 1518 se lee:

quisiera enbiarle algunos dátiles de los buenos, mas no he avido dicha en ellos, que dos cargas que me avían venido de la Zara, después questuvieron çerca de Tremeçen los parientes de aquel que ine los avía mercado los hizicron suhir y los apresentaron a Barbarroxa, de manera que pierdo los dátiles y los dineros. Reçiba vuestra merçed la buena voluntad ${ }^{73}$.

Antonio Riçio se iba del presidio poco después, dejando como factor a su hermano Jacobo. De éste y de Pero de Vivaldo sabemos que desempeñaron conjuntamente el cargo de arrendadores de los deréchos de la puerta de Tremecén, en la ciudad de Orán, y que, estando en ello, protagonizaron un duro enfrentamiento con las autoridades locales al negarse a que sus libros fueran examinados ${ }^{74}$.

Una relación incompleta del vecindario de Orán nos permite averiguar la identidad de algunos mercaderes genoveses que trataban en la plaza a fines de los años veinte: al ya conocido Pero de Vivaldo, hay que sumar los nombres de Juan Batista Spinola, Lequin de Arasio, Nicolás y Otabian de Forner. Todos ellos suministraban de vez en cuando ropa, calzado y, sobre todo, trigo y cebada para la provisión de la gente de guerra y vecinos estantes en Orán y Mazalquivir ${ }^{75}$. Cuando las circunstancias eran favorables, los cereales venían del país tremeceni según revela la actividad desplegada en dicho sentido por "miçer" Lequin de Arasio ${ }^{76}$. Pero si la cosecha local era insuficiente, $o$ su distribución se vela entorpecida por el deterioro de las relaciones fronterizas, en tal caso la única manera de evitar la especulación consistra en traer cereales del otro lado del mar ${ }^{77}$. Aunque el

\footnotetext{
${ }^{73}$ AGS, Estado, leg. 8337, lol. 1

${ }^{74}$ Parece que llevahan una doble contahilidad pues se hahla de un registro en papel, con letra ginovisca, y de otro, en castellano, cuyos contenidos no coincidian. Ch. de la VERONNE, op. cil., pp. 29 y 30.

${ }^{73}$ En 1527-1528 Cristóhal Rejón pagó a estos genoveses 1.679.374 maravedícs por los bastimentos que hahian traido a Orán. Ch. de la VI:RONNE, La población del presidio de Orán en 1527. "Revista de Archivos, Bihliotecas y Muscos", LXXXVI (1973), pp. 69-108.

${ }^{76}$ Actividad que simultancaha con la redención de cautivos cristianos. Cf. Oran el Themcen, pp. 88, 92 y 129.

${ }^{77}$ Nicolḱs y Otahian de Forner hicicron su agosto en 1529, que fue un año seco y de langostas en todo el reino de Tremecén. Ch. de la VERONNE, op. cit., p. 37.
} 
puerto más próximo era Cartagena, las mayores facilidades al respecto se encontraban en Málaga, donde el tesorero-pagador Cristóbal Rejón disponía de un factor encargado del abastecimiento del presidio ${ }^{78}$.

Hablando de Málaga, contamos con una fuente excepcional para conocer las relaciones que los genoveses de esta ciudad mantenfan con Orán. Se trata de los registros del Almirantazgo granadino para 1524-1526 y 1528 , los cuales reflejan el movimiento portuario malagueño y, lo que es más importante, la naturaleza y volumen de las exportaciones realizadas por el mismo. Según estos libros, la participación ligur en el tráfico con el presidio serf́a la siguiente ${ }^{79}$ :

\begin{tabular}{|c|c|c|}
\hline Fecha & Comerciante & Mercancias \\
\hline Septiembre de 1525 & Francisco de la Oliva & $\begin{array}{l}73 \text { serones de greva y } 8 \text { fardos de } \\
\text { paños }\end{array}$ \\
\hline Septieınbre de 1525 & Polo Catanco & 3 balas de paños \\
\hline Enero de 1526 & Polo "genovés" & $\begin{array}{l}150 \text { cargas de higos, } 100 \text { amrobas de } \\
\text { pasas, } 25 \text { de almendras; } 4 \text { balas de } \\
\text { paños y } 10 \text { costales de laca }\end{array}$ \\
\hline Enero de 1526 & Aınbrosio Spinola & $\begin{array}{l}20 \text { arrohas y } 3 \text { quintales de tocino; } 4 \\
\text { docenas de bermejuelos }\end{array}$ \\
\hline Octubre de 1526 & Francisco de la Oliva & 18 fardos de frisas \\
\hline Novieınbre de 1526 & Polo Catunico & 100 cahíces de trigo \\
\hline Diciembre de 1526 & Batista Salvagu & 39 cargas de pasa y 24 de higos \\
\hline Junio de 1528 & Ambrosio Adomo & 32 libras de seda \\
\hline Junio de 1528 & Aınbrosio Spinola & 2 quintales de cadarzos \\
\hline Septiembre de 1528 & Polo Catanco & I caja de bonetes \\
\hline
\end{tabular}

No parece que estemos ante un tráfico importante si se tiene en cuenta que parte de esas mercancías no iban destinadas a clientes musulmanes. Un tráfico que contrasta, además, con el que por entonces unía a Málaga con Vélez de la Gomera a pesar de las disposiciones dictadas para que todo el comercio norteafricano pasara por la plaza de Orán, según indicaba anteriormente. Francisco de la Oliva, Batista Salvago, su hermano Esteban y Blasio de Basiniana enviaban regularmente artículos que gozaban de gran

\footnotetext{
${ }^{78}$ En lo que toca a Cartagena, la escaser. de fucintes locales hace que resulte decepcionante, para lo que interesa aqui, la leclura de V. M(ONT(J)(), Carlagena en la época de Carlos $V$, Murcia, 1987.

${ }^{79}$ AGS, Consejo Real, leg. 93, fol. 4-II y III; Expedientes de Hacienda, leg. 123, fol. 2.
} 
demanda en el Magreb (laca, paños ingleses, algodón, seda en bruto o hilada, tártaro, rejalgar, azogue e incluso bordates) en barcos que volvían con cera, cueros, dátiles, plumas de avestruz y, probablemente, oro ${ }^{80}$. Los registros del Almirantazgo muestran cómo algunas de esas mercancías eran reexpedidas hacia otros lugares:

\begin{tabular}{|c|c|c|c|}
\hline Fechai & Comerciante & Género & Destino \\
\hline Murzo de 1525 & Batista Salvago & 350 cueros & Mallorea \\
\hline Mayo de 1525 & Butistu Sulvago & $\begin{array}{l}13 \text { medias botas, } 6 \text { botas grandes y } 6 \text { cuar- } \\
\text { terolas "todo de dátiles" }\end{array}$ & Flandes \\
\hline Julio de 1525 & Batista Salvago & 600 cueros & Cartagena \\
\hline Mayo de 1528 & Francisco de la Oliva & 15 botas de dátiles y 3 cajas de plumas & Cádiz \\
\hline
\end{tabular}

\section{CONSIDERACIONES FINALES}

Robert Ricard sostenf́a en un trabajo, hoy clásico, que el comercio exterior del reino de Fez en la primera mitad del s. XVI estaba orientado hacia el Atlántico por dos razones fundamentales: en principio, porque dicho comercio se encontraba en manos de genoveses de Cádiz y Lisboa; también, porque los puertos de Arcila, Salé y Larache eran más seguros y accesibles que el de Vélez de la Gomera, en la fachacia mediterránea de Marruecos ${ }^{81}$.

Como no parece probable que los genoveses de Málaga quisieran competir en este terreno con sus compatriotas residentes en otros puertos peninsulares -máxime si uno de ellos, Blasio de Basiniana, estaba asociado con comerciantes ligures de Cádiz-, habría que buscar otras razones que expliquen su interés por contratar en Vélez de la Gomera. Pues bien, creo haberlas encontrado en cierto informe enviado al rey Carlos desde Orán a mediados de los años treinta.

Se trata de un memorial remitido por el conde de Alcaudete, que habra sucedido al marqués de Comares como capitán general de Orán y Mazalçuivir, sobre la mala situación en que se encontraban los presidios.

\footnotetext{
${ }^{80} \mathrm{~J}$. E. LOPEZ DI: COCA, Vélez de la Gomera y su puerto durante la primera milad del siglo XVI, "Historia. Instituciones. Documentos" 20 (1993), pp. 225-227.

${ }^{81} \mathrm{Cf}$. Contribution à l'etude du commerce génois au Maroc durant la periode portugaise (1415-1550), "Eludes sur l'histoire des Portugais au Maroc", Coimbra, 1955, pp. 115-142.
} 
Por esas fechas los mercaderes europeos preferían acudir a los puertos de Argel y Vélez de la Gomera, donde se pagaban impuestos más suaves que los exigidos por los recaudadores de Orán: los hordates franceses, por ejemplo, abonaban entre el 6 y el $10 \%$ de su valor, mientras que en las plazas españolas estaban gravados con una tasa del $25 \%$. Buena parte de las mercanclas desembarcadas en Vélez de la Gomera eran traf́las posteriormente a Tremecén por intermediarios judíos y, lo que más irritaba a nuestro corresponsal, con ellas las nuevas de la corte española, que eran conocidas por el sultán antes de que el las recibiera por conducto oficial ${ }^{82}$.

Así pues, cabría concluir afirmando que los genoveses de Málaga no habłan perdido interés por negociar con el reino de Tremecén. La diferencia estriba en que ahora lo hacian por otros caminos más largos y complicados, pero, en apariencia, más seguros y provechosos.

\section{APÉNDICE DOCUMENTAL}

1505, febrero, 14. Orán.

Conosçimiento del arçediano de Bélez Málaga e de Lope de Vera de mill e seteçientos e çinquenta ducados que les enprestaron para la limosna del rey nuestro senor.

AGS, Casas y Sitios Reales, leg. 5, fol. 5.

Yo el arçediano de Belis Málaga, capellán del rey nuestro señor, e Lope de Vera, continuo de su real casa, damos fe como en la çibdat de Orán, después de aver acabado la limosna que trayamos de sus altezas para sacar cativos en la dicha çibdad de Orán, Nicolás Catanno, consol de su alteza, asf por el serviçio de Dios como porque ge lo rogamos de parte de su altesa oviese por bien de prestar la suma que abaxo se dirá para sacar dose ánimas, en que ay çinco moças de catorse fasta veynte años e los otros niños e niñas e mugeres, todos de collera, las quales estavan en gran-

\footnotetext{
${ }^{82}$ Según extractos que of rece Ch. de la VERONNE, op. cit., pp. 135 y 177.
} 
dísimo peligro, en poder de moros e judíos, para perder nuestra sancta fe católica, porque algunos niños e niñas no sabran ya nuestra lengua sino lo arávigo, e porque en esto tenemos por mui çierto su alteza es dello mui servido y que el dicho Nicolás Catanno, allende que de su préstamo sería muy bien pagado de su altesa ge lo terná en señalado serviçio, pues estos se an sacado después de fecha toda la costa de nuestro viaje, que fue la suma que costaron e pagó por ellos el dicho Nicolás Catanno mill e dosientos e çinquenta e çinco doblas de oro, y más por la salida de siete ánimas se pago al almoxarife de los derechos del rey ochenta e tres doblas e seis tomines, porque de los çinco restantes nosotros pagamos la salida; e más pagó el dicho Nicolás Catanno por un cautivo del almoxarife sesenta e seys doblas e media, el qual fue forçado conprar por rasón de otro cativo que sin liçençia era entrado en nao y lo quería deçender para cativarlo otia ves. E más le pedimos prestados para acabar de pagar nuestra limosna, que nos faltava, çiento e ochenta e çinco doblas e çinco tomines; que son por todas mill e quinientas e noventa doblas e siete ochavos de dobla de oro nuevas, que valen en Castilla por la justa estimaçion que entre los mercaderes se hase dies por çiento más que ducados, que montan mill e seteçientos e çinquenta ducados de oro e de peso, los quales plega a su altesa de los mandar pagar breve al dicho Nicolás Catanno o a Agostyn Ytalian, mercader genovés estante en esta corte, en su nonbre, o a quien por /él/ los oviere de aver.

Porque es asy verdad quel dicho Nicolao (sic) Catanno por servir a Dios e a sus altesas ha enprestado el dicho dinero para la dicha limosna, nos, los susodichos, dimos esta fe e lo firmamos aqui de nuestros nonbres. Fecho en la çibdad de Orán a catorze días del mes de febrero año de mill e quinientos e çinco años. El arçediano de Beles. Lope de Vera.

\section{RÉSUMÉ}

A la fin du XVe siècle, le commerce génois avec Tlemcen était exercé fondamentalement vers le port d'Oran. A ce trafic participaient, à la fois, les marchands de Gênes, ceux qui employaient les bateaux navigant per costeriam et, certainement, les Génois habitants des royaumes de Valence et Castille, en particulier ceux de Málaga. Après la conquête d'Oran 
(1509), le commerce génois fut gêné par les conséquences de la désastreuse politique espagnole. Malgré cela, ces marchands ne renonçaient pas à trafiquer avec Tlemcen, bien qu'ils fussent obligés de suivre voies plus longues et incommodes.

\section{SUMMARY}

At the end of the XVth century the Genoese trade with Tremecen was mainly carried through the port of Oran. Merchants from Genoa and those who rented ships travelling per costeriam, together with the Genoese already living in the Kingdoms of Valencia and Castle, and particularly those in Malaga shared in this trade. After the conquest of Oran in 1509, the Genoese commerce will be very much harmed by the disastrous Spanish policy. However, these merchants did non give up trading with Tremecen although they had to follow longer and more unconfortable ways. 